\title{
Realismo ingênuo e objetos da consciência alucinatórios são conciliáveis?
}

\author{
Are naive realism and hallucinatory consciousness
}

objects reconcilable?

DANIEL BORGONIDa

\section{Resumo}

O realismo ingênuo é a concepção da percepção verídica segundo a qual a experiência perceptiva é fundamentalmente relacional. Objetos físicos e suas propriedades têm um papel constitutivo na experiência perceptiva e determinam seu caráter fenomênico. Segundo o argumento causal, porém, podemos produzir a mesma experiência que ocorre quando vemos um objeto físico sem o objeto físico. Em defesa do realismo ingênuo frente ao argumento causal, Johnston (2004) propõe a teoria do perfil sensível. Meus objetivos são mostrar que sua estratégia de defesa pode ser caracterizada como um disjuntivismo fenomênico, além de defender que a teoria do perfil sensível não garante a prioridade de objetos físicos sobre objetos da consciência alucinatórios na determinação fenomênica da experiência perceptiva verídica. Por isso, a teoria do perfil sensível não tem êxito na defesa do realismo ingênuo contra o argumento causal.

Palavras-chave: Percepção verídica. Alucinação. Disjuntivismo. Caráter fenomênico. Johnston.

\section{Abstract}

Naive realism is the conception of veridical perception according to which perceptual experiences are fundamentally relational. Physical objects and their properties have constitutive role in perceptual experience and they determine its phenomenal character. However, according to the causal argument we can produce the same experience that occurs when someone sees a physical object without the physical object. In defense of

\footnotetext{
a Universidade de São Paulo, São Paulo, SP, Brasil. Doutor em Filosofia, e-mail: dborgoni@hotmail.com
} 
naïve realism against the causal argument, Johnston (2004) presents his sensible profile theory. My aims are to show that his strategy of defense can be characterized as a phenomenal disjunctivism and to defend that his theory fail to ensure the priority of physical objects over hallucinatory consciousness objects on the phenomenal determination of veridical perceptual experience. Hence, the sensible profile theory does not have succeed in defending naive realism against the causal argument.

Keywords: Veridical perception. Hallucination. Disjunctivism. Phenomenal character. Johnston.

\section{Introdução}

Por meio da percepção sensível, um organismo com capacidades sensoriais, como um ser humano, é informado sobre objetos ou eventos do mundo. Essa informação, porém, deve ser apreendida conscientemente pela pessoa para que se possa dizer que ela tem uma experiência. Por ser uma experiência consciente, a percepção sensível comum ${ }^{1}$ envolve uma fenomenologia, ou caráter fenomênico, que é como as qualidades sensíveis que experienciamos aparecem à consciência da pessoa. Por exemplo, ao ver uma banana madura, a cor amarela aparece à pessoa sob uma perspectiva subjetiva, ou perspectiva de primeira pessoa. Desse modo, o caráter fenomênico diz respeito à natureza das próprias experiências perceptivas verídicas ${ }^{2}$.

A percepção verídica parece nos colocar em contato direto com objetos independentes da mente ${ }^{3}$, ou seja, quem percebe parece estar diretamente consciente de objetos cuja existência independe da sua consciência. Estar em contatoperceptivo direto significa estar numa relação perceptiva sem entidades mediando quem percebe e o objeto percebido, tais como os sense data ${ }^{4}$. Objetos físicos também parecem contribuir

\footnotetext{
${ }^{1}$ Por 'percepção sensível comum' me refiro aos casos paradigmáticos de percepção. Assim, estão excluídos casos de visão cega, patologia na qual a pessoa adquire informação visual sobre alguma parte do cenário sem ter uma experiência consciente, ou seja, é um processamento de informação visual com ausência de fenomenologia.

2 Poderei me referir à "experiência perceptiva verídica" somente por "experiência perceptiva".

${ }^{3}$ Me refiro aos objetos ordinários do nosso cotidiano, como mesas, cadeiras, livros e maçãs. Também me referirei a eles como objetos físicos ou objetos no mundo.

${ }^{4}$ No debate atual em filosofia da percepção, costuma-se caracterizar os sense data, ou dados dos sentidos, como entidades mentais e privadas que caracterizariam a natureza das experiências, desde uma alucinação até uma percepção verídica. A percepção verídica estaria
} 
para a constituição das experiências perceptivas, de modo que a experiência parece ser fundamentalmente uma questão da relação entre uma consciência e o objeto físico. Isso implica que o objeto físico tem papel na determinação do caráter fenomênico perceptivo. Se assim for, o estado mental perceptivo depende de objetos físicos e suas propriedades para sua ocorrência. Essa concepção da percepção verídica é usualmente denominada "realismo ingênuo" ou "visão relacional" e envolve a intuição de que a natureza da experiência perceptiva é fundamentalmente relacional.

Devemos investigar a visão relacional da percepção por várias razões. Uma delas é porque ela oferece um relato satisfatório sobre a particularidade das experiências perceptivas verídicas. O objeto físico faz diferença na individuação da experiência perceptiva verídica, na medida em que tem papel constitutivo na própria experiência. Uma concepção da percepção deve explicar também como poderíamos justificar nossas crenças empíricas dando-lhes o estatuto de "conhecimento". Nesse sentido, a visão relacional preenche o hiato entre aparência e realidade ao propor que objetos ordinários estão diretamente presentes à mente. Com isso, temos uma justificação para o conhecimento sobre uma base objetiva. Vemos, então, que a elucidação do problema metafísico sobre a natureza das experiências perceptivas pode contribuir para o esclarecimento do problema epistemológico da justificação de crenças sobre o mundo externo.

Se objetos físicos são fundamentais para a natureza da percepção verídica, o estado mental perceptivo tem de ser diferente do estado mental alucinatório. Contudo, alucinações introspectivamente indiscrimináveis de percepções verídicas, isto é, alucinações nas quais a pessoa não consegue saber por meio da reflexão sobre sua experiência que está alucinando, são postas a favor da tese do máximo fator comum entre alucinações e percepções, segundo a qual ambas as experiências compartilham o mesmo estado mental. Dado a indiscriminabilidade introspectiva alucinatória e considerando que toda percepção verídica pode ter como contrapartida uma alucinação indiscriminável, existiria um máximo fator comum que caracterizaria ambas essas experiências como experiências da mesma natureza. Em outros termos,

condicionada à consciência dos sense data e, assim, os objetos imediatos da percepção não seriam objetos físicos. 
a partir da indiscriminabilidade introspectiva alucinatória infere-se a indiscriminabilidade ontológica entre estados mentais. Se a pessoa que alucina está no mesmo estado mental da pessoa que percebe, o realismo ingênuo é falso.

Em contraponto à tese do máximo fator comum, filósofos e filósofas têm invocado o disjuntivismo, teoria que defende que percepções e alucinações são tipos de experiências radicalmente diferentes por não compartilharem o mesmo estado mental, ainda que o estado mental alucinatório pareça indiscriminável do estado mental perceptivo.

Embora tenha aparecido de modo embrionário em Austin (1962), o disjuntivismo foi inicialmente explicitado por Hinton (1967). Disjuntivistas questionam o que sustenta o máximo fator comum, isto é, a inferência da indiscriminabilidade introspectiva para a indiscriminabilidade ontológica entre estados mentais. Da experiência visual de uma pessoa que disse ter visto $\mathrm{X}$, o que estaríamos autorizados a afirmar é: ou a pessoa viu de fato X, e teve uma percepção verídica, ou pareceu-lhe ver X, e teve uma alucinação. Não se segue necessariamente de uma alucinação indiscriminável de uma percepção que ambas experiências tenham alguma propriedade em comum que as caracterize como experiências da mesma natureza.

Considerando que a inferência que sustenta a tese do máximo fator comum não é dada, disjuntivistas negam que ambos os lados da disjunção tenham um estado mental em comum que nos leve a caracterizar uma alucinação e uma percepção como experiências da mesma natureza. Isso implica que disjuntivistas devem explicar o que faz com que uma alucinação pareça indiscriminável de uma percepção sem recorrer a um máximo fator comum entre essas experiências.

Diversas variantes do disjuntivismo foram desenvolvidas, conforme os problemas filosóficos que estavam sendo tratados, mas podemos dividi-lo em epistêmico e metafísico. O disjuntivismo epistêmico trata de questões relacionadas ao conhecimento, como o problema do mundo exterior. O estado mental alucinatório seria diferente do estado mental perceptivo, pois a garantia epistêmica que uma pessoa tem quando alucina seria mais fraca do que a evidência que uma pessoa tem nos casos verídicos. Já o disjuntivismo metafísico trata da constituição das experiências 
perceptivas e defende que o estado mental perceptivo difere do estado mental alucinatório porque tem constituintes diferentes.

Como o realismo ingênuo é uma concepção sobre a estrutura metafísica perceptiva, isto é, sobre a constituição fundamental da experiência perceptiva verídica, a defesa do realismo ingênuo é usualmente feita pelo disjuntivismo sobre a fenomenologia, doravante denominado "disjuntivismo fenomênico", segundo o qual percepções verídicas e alucinações não compartilham o mesmo caráter fenomênico, ainda que uma alucinação indiscriminável pareça ter a fenomenologia da respectiva percepção verídica.

$\mathrm{Na}$ defesa do realismo ingênuo frente à tese do máximo fator comum entre alucinações e percepções, disjuntivistas fenomênicos exploram o seguinte raciocínio: como a inferência entre a indiscriminabilidade introspectiva e a indiscriminabilidade fenomênica não está dada, não se segue que alucinações indiscrimináveis compartilham o caráter fenomênico que faz das percepções verídicas experiências sui generis. A indiscriminabilidade alucinatória proviria da incapacidade introspectiva de a pessoa discriminar sua alucinação de uma percepção verídica. Ou seja, além de levar a pessoa à falsa crença de que está percebendo objetos externos, uma alucinação indiscriminável leva quem alucina a atribuir, erroneamente, fenomenologia perceptiva à experiência alucinatória. Portanto, para disjuntivistas fenomênicos, a introspecção não é um sentido interno por meio do qual a pessoa observa os próprios estados mentais, capacitando-a a conhecer as propriedades da sua experiência ou reconhecer sua ausência.

Contudo, a tese do máximo fator comum pode ser defendida por meio de um argumento mais forte e convincente: o argumento causal da alucinação. Ao utilizar fatos causais sobre a percepção para sustentar que a pessoa que alucina pode estar no mesmo estado mental que estaria caso estivesse tendo uma percepção verídica, o argumento causal é uma séria ameaça ao realismo ingênuo, pois nega que objetos independentes da mente têm papel determinante no caráter fenomênico perceptivo.

Uma das principais defesas do realismo ingênuo frente ao argumento causal é feita por Mark Johnston (2004). Embora Johnston (2004) não associe sua posição teórica com o disjuntivismo, apresentarei razões que justificam denominá-la como uma variante do disjuntivismo fenomênico. Como veremos, ele endossa o cerne do 
disjuntivismo fenomênico, qual seja, que uma alucinação indiscriminável não tem a fenomenologia da correspondente percepção verídica. E, tal como Martin (2004, 2006) e Fish (2008, 2009), ambos declaradamente disjuntivistas, Johnston (2004) defende a visão relacional da percepção. Esse é o primeiro objetivo deste artigo.

Meu segundo objetivo é mostrar que a teoria do perfil sensível, apresentada por Johnston (2004) na defesa do realismo ingênuo contra o argumento causal, enfrenta dois problemas. O primeiro é o de não explicar como a pessoa que alucina tem consciência de qualidades não instanciadas. O segundo problema é que a teoria do perfil sensível é incapaz de mostrar que objetos físicos são fundamentais para a constituição da experiência perceptiva verídica e para a determinação do seu caráter fenomênico.

O artigo é estruturado da seguinte maneira. Na seção 1 apresentarei os compromissos teóricos aos quais o realista ingênuo adere, com o objetivo de entendermos como o argumento causal ameaça o realismo ingênuo. A seção 2 é dedicada à formalização e escrutínio do argumento causal. Na seção 3 apresentarei os motivos que levam Johnston (2004) a caracterizar positivamente as alucinações, ou seja, a defender que a pessoa que alucina encontra itens mentais genuínos. A seção 4 é dedicada à apresentação da teoria do perfil sensível e a consequente resposta ao argumento causal. $\mathrm{Na}$ seção 5 apresentarei os dois problemas com teoria do perfil sensível aos quais me referi e que me levaram a concluir que a teoria de Johnston (2004) não é exitosa na defesa do realismo ingênuo contra o argumento causal. Por fim, na seção 6 farei a conclusão.

\section{A natureza da percepção verídica}

Embora discordem sobre a natureza das experiências alucinatórias e sobre o que faz com que uma alucinação seja introspectivamente indiscriminável de uma percepção verídica, Martin (2004, 2006), Fish (2008, 2009) e Johnston (2004) concordam sobre a estrutura metafísica da percepção verídica, ou seja, sobre qual é a natureza da experiência perceptiva verídica. Nesse sentido, para Martin: 
[...] algumas experiências sensoriais são relações com objetos independentes da mente. Isto quer dizer que, tomando as experiências como episódios e eventos, o realista ingênuo supõe que alguns episódios têm como constituintes objetos independentes da mente (MARTIN, 2006, p. 354).

A importância de objetos físicos na determinação fenomênica é posta por Fish:

[...] nós deveríamos entender a afirmação do realista ingênuo de que objetos externos e suas propriedades circunscrevem os contornos da experiência consciente da pessoa: eles circunscrevem os contornos da experiência consciente da pessoa por, de fato, serem os contornos da experiência consciente da pessoa (FISH, 2009, p. 6).

Por sua vez, Johnston afirma que:

Ver um objeto não é o próximo evento depois que o sistema visual opera. Ver um objeto é um evento materialmente constituído pelo longo processo visual que conecta o objeto visto ao estado final do sistema visual $[. .$.$] nesse sentido, ver é mais do que o trabalho solitário do sistema visual$ ou, de fato, de todo o cérebro (JOHNSTON, 2004, p. 139).

Martin (2004, 2006), Fish (2008, 2009) e Johnston (2004) defendem a "visão relacional" da percepção. A percepção verídica teria um caráter relacional no qual a experiência é uma mera relação entre particulares físicos e suas propriedades e uma pessoa, ou seja, nada mais caracterizaria a experiência perceptiva verídica além desse caráter relacional. Não existiriam conteúdos representacionais caracterizando a estrutura metafísica perceptiva, nem sense data mediando a relação entre quem percebe e o objeto percebido. Por isso, na visão relacional da percepção, objetos físicos e suas propriedades têm um papel fundamental na constituição experiencial e na determinação fenomênica da percepção verídica.

Se não existe mediação entre a pessoa e o objeto percebido e se a percepção é uma mera relação entre objetos físicos e uma pessoa, a experiência é suficiente para o contato perceptivo. A suficiência da experiência em colocar a pessoa em contato com o objeto no mundo significa que a experiência não é entendida como um elemento independente da estrutura perceptiva, tal como propõe o conjuntivismo ${ }^{5}$. Desse modo, experiências perceptivas não têm qualquer papel explicativo autônomo sobre suas naturezas, pois a concepção da experiência depende da concepção que se tem da percepção.

\footnotetext{
${ }^{5}$ A teoria dos dados dos sentidos é um exemplo de teoria conjuntivista.
} 
Como defende que a natureza da experiência perceptiva verídica depende de objetos físicos e, portanto, o caráter fenomênico perceptivo seria realizável somente na presença destes, Johnston (2004) se contrapõe à identificação do evento mental que ocorre na percepção verídica com eventos cerebrais e nega a sobreveniência do mental em relação ao cerebral ${ }^{6}$. No fisicalismo de identidade, experiências perceptivas são eventos ou estados mentais que ocorrem no final da cadeia causal perceptiva, pois existe uma relação de identidade entre o estado mental perceptivo e o estado cerebral correlato. Essa identificação não pode ser endossada por Johnston (2004), pois reduziria a experiência ao que ocorre no cérebro, tornando o objeto físico não necessário para a constituição experiencial. Na sobreveniência do mental em relação ao cerebral, as propriedades de baixo nível são os estados cerebrais e o que compõe o estado mental perceptivo são propriedades de alto nível. Estados mentais perceptivos não seriam redutíveis a estados cerebrais, mas seriam dependentes e determinados por estados cerebrais, violando a tese realista ingênua de que objetos físicos são necessários para a determinação e constituição da experiência perceptiva verídica.

\section{0 argumento causal}

Segundo o argumento causal, poderíamos obter a experiência consciente que ocorre na percepção verídica na ausência do objeto físico desde que uma alucinação tenha as condições causais proximais relevantes da correspondente percepção verídica. Por isso, a tese do máximo fator comum entre alucinações e percepções é motivada pelo argumento causal. Tratemos desse argumento com mais vagar.

Simplificadamente, mas suficiente para os propósitos deste artigo, a cadeia causal perceptiva visual pode ser descrita do seguinte modo: a luz refletida no objeto físico atinge a retina estimulando os nervos ópticos que se ligam com o núcleo geniculado lateral do tálamo que, por sua vez, se conectam com o córtex visual primário. Então, o córtex visual primário envia informações relativas à visão

\footnotetext{
${ }^{6}$ A sobreveniência é uma relação de covariação e dependência de fenômenos de alto nível e fenômenos de baixo nível, no sentido de que, fixadas as propriedades de baixo nível A, as propriedades de alto nível B são fixadas. Cf. KIM, 1993, p.140.
} 
parcialmente processadas para diversas regiões do córtex associadas à visão ${ }^{7}$ e voilà a pessoa tem uma experiência perceptiva.

Formalizando o argumento causal:

(1) $\mathrm{Na}$ percepção verídica de um objeto físico $\mathrm{O}$ (ou elo distal da cadeia causal), uma pessoa P tem uma experiência E.

(2) A pessoa P pode ter uma experiência indiscriminável — uma alucinação — da percepção verídica do objeto físico $\mathrm{O}$ na ausência do objeto físico $\mathrm{O}$ se ativarmos algum elo causal proximal tal como o elo causal proximal é ativado na percepção verídica do objeto $O$.

(3) Se os estados neurais da alucinação visual do objeto $O$ são os estados neurais da percepção verídica de $\mathrm{O}$, a pessoa $\mathrm{P}$ quando alucina tem a experiência E.

(4) A pessoa $\mathrm{P}$ tem a experiência $\mathrm{E}$ na alucinação do objeto $\mathrm{O}$ e na percepção verídica do objeto $\mathrm{O}$.

(5) Se é possível termos uma experiência $\mathrm{E}$ sem o objeto físico $\mathrm{O}$, o objeto físico $\mathrm{O}$ não é necessário para que a pessoa $\mathrm{P}$ tenha a experiência $\mathrm{E}$.

(6) Alucinações e percepções são experiências da mesma natureza.

(7) O realismo ingênuo é falso.

Segundo o argumento causal, e considerando a integridade do sistema visual, ao ativarmos algum elo proximal da cadeia causal perceptiva visual, como os nervos óticos, do mesmo modo como os nervos óticos são estimulados na percepção verídica, garantiríamos que os estágios posteriores da cadeia causal àquele estágio que foi estimulado seriam os mesmos. Como replicamos as condições causais proximais relevantes de uma percepção verídica, produziríamos uma alucinação causalmente condizente, isto é, uma alucinação introspectivamente indiscriminável produzida através das mesmas condições causais proximais de uma percepção verídica. Da indiscriminabilidade entre os estados neurais alucinatórios e os estados neurais perceptivos, infere-se que a pessoa que alucina tem a mesma experiência que teria na

\footnotetext{
${ }^{7}$ Cf. O'SHEA, 2010 [2005].
} 
respectiva percepção verídica. Em outras palavras, o mesmo estado cerebral garantiria a identidade experiencial e, assim, a identidade fenomênica entre percepção e alucinação. Se não precisamos do objeto físico para a ocorrência da experiência perceptiva verídica, objetos físicos não são necessários para a natureza da percepção verídica, tornando falso o realismo ingênuo.

Para bloquear a conclusão do argumento causal, quem defende o realismo ingênuo pode contestar a premissa (2) ou a premissa (3). Contra a segunda premissa, poderia alegar que experimentalmente ainda não conseguimos replicar uma alucinação causalmente condizente. Entretanto, entendo que essa não seria a melhor estratégia contra o argumento causal, por dois motivos: i) não elimina a possibilidade das alucinações introspectivamente indiscrimináveis, na medida em que talvez um dia consigamos simular em laboratório precisamente as condições causais proximais de uma percepção verídica na ausência do objeto físico e; ii) Evidências empíricas obtidas por Ffytche (2013, p. 54), durante o escaneamento do cérebro de uma pessoa alucinando, mostram atividade cerebral na área de especialização do seu córtex visual similar àquela quando a pessoa percebe veridicamente. Quando a pessoa alucinava um rosto, a área do córtex visual especializada no reconhecimento facial estava ativada tal como quando a pessoa está vendo um rosto físico. Desse modo, contestar a premissa (2) deixa o realista ingênuo numa posição insegura.

Talvez pelos motivos citados acima, relacionalistas costumam objetar a terceira premissa. A premissa (3) carrega o princípio da mesma causa, mesmo efeito: como alucinações e percepções podem ter as mesmas causas proximais, isto é, os elos proximais da cadeia causal de ambas experiências podem ser os mesmos, as experiências teriam a mesma natureza, pois as mesmas causas devem produzir os mesmos efeitos. É o princípio da mesma causa, mesmo efeito que sustenta a inferência que parte da indiscriminabilidade entre estados neurais alucinatórios e estados neurais perceptivos para concluir que uma alucinação causalmente condizente compartilha com a correspondente percepção verídica o mesmo estado mental. Por conseguinte, endossar o princípio da mesma causa, mesmo efeito, é colocar em xeque o realismo ingênuo.

Contestando a premissa (3), Johnston afirma que "a relação entre ver um objeto e o longo processo físico [perceptivo causal] [...] não é uma relação entre o Rev. Filos., Aurora, Curitiba, v. 33, n. 59, p. 652-676, mai./ago. 2021 
primeiro efeito mental e o antecedente processo físico que causa o primeiro efeito mental” (2004, p. 138-139). Desse modo, condições não causais - o objeto físico e suas propriedades - interfeririam na natureza da experiência ocorrente na percepção verídica. Não se trata de negar o princípio da mesma causa, mesmo efeito quando aplicado às conexões entre leis físicas e objetos públicos, mas de negar que algumas conexões causais de natureza psicofísica sejam regidas pelo referido princípio. Também não se trata de negar que a percepção sensível não esteja sujeita à ordem causal em absoluto, mas de negar que esteja submetida a ordem causal tal como posta pelo princípio da mesma causa, mesmo efeito, doravante denominado "princípio causal geral".

Desse modo, a ocorrência da percepção verídica não estaria circunscrita somente ao final da cadeia causal perceptiva, pois objetos físicos seriam condições não causais que constituem a experiência perceptiva verídica ${ }^{8}$. Isso resguarda a visão relacional da percepção, na medida em que processos cerebrais não são suficientes para a realização da fenomenologia perceptiva.

\section{A caracterização positiva das alucinações}

Embora concordem sobre a natureza da percepção verídica, disjuntivistas fenomênicos discordam sobre a natureza da experiência alucinatória. Contrariamente a Martin (2006) e Fish (2008), Johnston (2004, p. 120) afirma que a pessoa que alucina encontra itens mentais genuínos, ou objetos da consciência. Dois são os motivos que o levam a defender uma caracterização positiva das alucinações: i) a natureza característica da experiência alucinatória e; ii) transições introspectivas sem rupturas de alucinações para percepções e vice-versa. Esses motivos também levam Johnston (2004) a afirmar que o disjuntivismo, quando nega a existência de itens mentais genuínos nas alucinações, é incapaz de explicar i) e ii) ${ }^{9}$.

\footnotetext{
${ }^{8}$ Vários filósofos e filósofas contestam o princípio da mesma causa, mesmo efeito ao tratarem de outras questões filosóficas, isto é, afirmam que certos eventos mentais têm condições não causais necessárias para sua ocorrência. Os externalistas sobre o conteúdo mental são um exemplo.

${ }^{9}$ Embora Johnston (2004, p. 121) não explicite qual o tipo de disjuntivismo está criticando, o seu alvo são os disjuntivismos de Martin $(2004,2006)$ e Fish $(2008,2009)$. Por negarem qualquer 
O primeiro motivo pelo qual devemos caracterizar positivamente a natureza alucinatória seria porque a alucinação admite a análise ação-objeto, isto é, alucinações exibem itens demonstrativos. Isso mostraria que a experiência alucinatória é direcionada para algo mental. Exemplificando, consideremos a pergunta de Macbeth: "É um punhal isso que vejo diante de mim [...] ou uma visão fatal procedendo do meu cérebro oprimido pelo calor?” (JOHNSTON apud SHAKESPEARE, 2004, p. 127, grifos do autor).

A experiência demonstra para Macbeth um item que identifica sua categoria, de modo que, qualquer que seja a resposta para a pergunta de Macbeth, ou seja, quer esteja alucinando ou vendo um punhal, existe um item que se apresenta a Macbeth e que a ele é demonstrado. O mesmo não ocorre quando alguém está supostamente procurando a lança que perfurou Jesus quando estava na cruz. Considere a pergunta: "O que estou buscando é uma lança real, ou meramente uma lendária ficção de um devoto?" (JOHNSTON, 2004, p. 128). Neste caso, não se trata de uma ocorrência demonstrativa, pois não existe um item que se apresenta à consciência da pessoa que procura a lança, isto é, não existe algo que ocupa a atenção visual no qual a pessoa identifique sua categoria. Embora a pessoa possa imaginar a lança, isso é bastante diferente de alucinar uma lança, uma vez que somente a alucinação pode se passar por uma percepção verídica. Diferentemente do que acontece na experiência alucinatória, não precisamos adotar uma análise ação-objeto no caso da lança. Se o verbo ver se refere sempre a um item demonstrativo, o verbo buscar nem sempre está em relação a um item demonstrativo e, no caso da lança, o verbo buscar não está efetivamente em relação a um item demonstrativo.

Outro motivo que leva Johnston (2004) a defender a caracterização positiva alucinatória é porque se negarmos a presença de objetos da consciência na alucinação, somos incapazes de explicar transições sem ruptura no caráter fenomênico que poderiam ocorrer entre alucinações e percepções, e vice-versa. Ou seja, a pessoa não perceberia quando deixou de alucinar e começou a ver, por exemplo. Para mostrar isso, Johnston (2004, p. 122) recorre a um experimento mental.

tipo de caracterização positiva à natureza alucinatória, é usual denominá-los "disjuntivismos radicais". 
Um cirurgião está operando um aneurisma no córtex visual e precisa do relato do paciente sobre o que ocorre no seu campo visual no decorrer da cirurgia. Após reduzir o desconforto com algum analgésico para abrir o crânio do paciente, o cirurgião escurece a sala apagando as luminárias do teto. Ao aplicar um estímulo elétrico no córtex visual, o paciente relata que as luzes do teto estão acessas. Ora, a pessoa está alucinando luzes no teto, pois elas continuam apagadas. O cirurgião, então, resolve acender as luminárias de tal modo que o paciente não perceba qualquer diferença de intensidade luminosa. Embora as luzes estejam agora acessas, a pessoa continua alucinando luzes acessas no teto. Como continua alucinando, o paciente tem uma alucinação verídica, pois existem luzes acessas com a mesma intensidade luminosa e exatamente onde o paciente as alucina. Por fim, o médico deixa de estimular o córtex visual do paciente, que deixa de alucinar luzes no teto, passando a percebê-las veridicamente.

No entender de Johnston (2004, p. 122), as transições experienciais do primeiro para o segundo estágio e do segundo para o terceiro estágio do experimento poderiam ocorrer sem rupturas do caráter fenomênico. Se existem diferenças entre os processos cerebrais alucinatórios e os processos cerebrais perceptivos, estes não fariam diferença ao nível da experiência consciente, pois a pessoa não percebe a transição fenomênica entre as experiências que teve. Assim, deve existir algo responsável por tornar indiscrimináveis introspectivamente a alucinação da correspondente percepção ao nível da experiência. Então, “com quais os tipos de coisas com as quais a experiência visual pode estar em relação de modo que no caso da alucinação e no caso da visão não exista diferença que a pessoa possa discriminar?” (JOHNSTON, 2004, p. 123).

Se não existem rupturas fenomênicas entre alucinações e percepções, deve existir algo no nível mental que explique a transição experiencial imperceptível à pessoa submetida ao experimento. Em outras palavras, para explicar a indiscriminabilidade alucinatória, precisamos de objetos da consciência nas alucinações.

Considerando que alucinações admitem uma análise ação-objeto, Johnston (2004, p. 129-134) argumenta que alucinações teriam três características: 1) alucinações não fornecem conhecimento de re sobre particulares físicos; 2) alucinações 
podem fornecer conhecimento de re sobre qualidades e; 3) como particulares físicos não podem ser objetos primários da alucinação, pois não existem objetos físicos na alucinação, Johnston (2004, p. 132) os denominada “objetos secundários da alucinação". São os objetos primários da alucinação, doravante denominados “objetos da consciência alucinatória", o fator comum entre percepções e alucinações ${ }^{10}$.

Entretanto, recorrer a itens mentais para explicar a indiscriminabilidade alucinatória é endossar a existência de um fator comum entre alucinações e percepções, qual seja, o objeto da consciência alucinatório. Ora, se Johnston (2004) quer defender o realismo ingênuo, como garantir que os objetos da consciência alucinatórios não são o máximo fator comum entre alucinações e percepções?

É por meio da teoria do perfil sensível que Johnston (2004) conciliará o fator comum compartilhado entre alucinações e percepções com a tese segundo a qual objetos físicos determinam o caráter fenomênico da experiência perceptiva verídica, portanto, fundamentais para a natureza da percepção verídica.

\section{A teoria do perfil sensível}

Segundo Johnston (2004), para não sucumbirmos ao argumento causal ao endossarmos um fator comum entre alucinações e percepções, devemos:

[...] encontrar um modo de combinar o objeto comum da consciência que está supostamente presente na alucinação e na visão com a não menos consciência direta dos objetos externos que são definidores da visão [...] nós necessitamos colocar o objeto comum da consciência junto aos objetos característicos que nós vemos sem meramente anexar o objeto comum da consciência aos objetos externos que nós vemos (JOHNSTON, 2004, p. 120).

Embora o objeto da consciência com o qual a pessoa se defronta na alucinação seja comum às alucinações e percepções, esse objeto da consciência deve ser tão somente um fator comum entre percepções e alucinações. Ou seja, se trata de admitir a existência de um objeto da consciência alucinatória comum às experiências

\footnotetext{
${ }^{10}$ Johnston (2004, p. 143) afirma que "objetos secundários da alucinação" são somente um modo de falar sobre particulares físicos inexistentes na alucinação, mas que parecem existir para quem alucina. Os verdadeiros objetos da alucinação são os 'objetos primários da alucinação'. Por isso, os denominarei de "objetos da consciência alucinatórios".
} 
perceptivas verídicas, sem que esse fator comum determine a natureza da experiência ocorrente na percepção verídica.

$\mathrm{O}$ ato da consciência (ou estado mental) alucinatório seria comum a percepções e alucinações, mas não ameaçaria o realismo ingênuo, pois se os "atos da consciência são plausivelmente individuados pelos seus objetos diretos, o ato da consciência da percepção verídica seria um ato da consciência não idêntico a qualquer ato da consciência comum à visão e à alucinação" (JOHNSTON, 2004, p. 116). Desse modo, não são endossados o conjuntivismo e o disjuntivismo radical ${ }^{11}$.

No entanto, o estado mental perceptivo não pode ser completamente diferente do estado mental alucinatório. No entender de Johnston (2004, p. 116), defender a existência de estados mentais completamente diferentes para explicar a percepção verídica e explicar o elemento comum a alucinações e percepções, seria ter de afirmar que na percepção verídica o cérebro inspeciona toda a cadeia causal, escolhendo o estado mental perceptivo ao encontrar o objeto físico, em detrimento do estado mental alucinatório. Em outras palavras, seria supor que o cérebro inspeciona os elos causais da cadeia perceptiva e, ao determinar que o objeto encontrado é o objeto físico, seleciona o estado mental causado pelo objeto físico. Essa explicação não parece razoável, pois seria endossar a existência de alguma espécie de ação à distância na percepção verídica ${ }^{12}$.

Se se defende a existência de um estado mental perceptivo e de um estado mental alucinatório e se o estado mental perceptivo não pode ser completamente diferente do estado mental alucinatório, o estado mental alucinatório é uma parte do estado mental perceptivo. Então, a defesa conjunta do realismo ingênuo com uma fenomenologia positiva para alucinações requer que o estado mental perceptivo não seja completamente distinto do estado mental alucinatório. Assim, “o fator comum

\footnotetext{
${ }^{11}$ Para o conjuntivista existe somente um tipo de ato da consciência, pois existe um máximo fator comum que caracteriza experiências alucinatórias e experiências perceptivas. Para os disjuntivistas radicais, existe somente um ato da consciência restrito às percepções verídicas, pois nega-se que alucinações tenham objetos da consciência.

${ }^{12}$ Lembremos que o disjuntivista não nega que os estados cerebrais envolvidos na alucinação não possam ser os mesmos estados cerebrais ocorrentes na percepção verídica. Daí a necessidade de que, caso fosse defendido que os atos da consciência na alucinação e na percepção fossem completamente distintos, teríamos de admitir que o cérebro inspeciona toda a cadeia causal à procura do objeto físico.
} 
[entre uma alucinação e uma percepção] é meramente uma parte do que eu estou consciente no caso verídico" (JOHNSTON, 2004, p. 148).

Mas como a existência de um elemento comum entre alucinações e percepções pode ser combinado com o realismo ingênuo, sem que o fator comum determine completamente a fenomenologia perceptiva? Busquemos essa resposta na teoria do perfil sensível.

Johnston (2004, p. 134) denomina "perfil sensível" ao campo sensível ou cenário com o qual a pessoa se depara numa percepção verídica. O perfil sensível é descrito como um campo sensível com propriedades e relações das quais a pessoa está consciente quando tem uma percepção verídica, cuja constituição é parcialmente qualitativa e parcialmente relacional. Na percepção verídica, todas as qualidades e relações que aparecem para a pessoa são instanciadas no mundo e os objetos vistos são particulares espaço-temporais instanciando complexos de qualidades sensíveis e relações.

O modo como as coisas aparecem na percepção verídica envolve um layout, isto é, os particulares implicados em um perfil sensível, quaisquer que sejam, estão num certo tempo e em certa posição do espaço tridimensional, estando a certa distância e direção da pessoa quando tem a percepção verídica. O layout é "antes um universal do que um particular" (JOHNSTON, 2004, p. 135). Portanto, diferentes particulares podem ser instanciados num mesmo layout e o perfil sensível envolve mais que um layout, pois "inclui a condição adicional que o layout relacional seja preenchido com um ou outro particular com certas qualidades" (JOHNSON, 2004, p. 135).

$\mathrm{Na}$ alucinação "nós estamos meramente conscientes das partes qualitativas estruturadas de tais perfis sensíveis" (JOHNSTON, 2004, p. 137). Assim, alucinações são experiências de natureza diferente das percepções verídicas. O estado mental alucinatório não seria completamente distinto do estado mental perceptivo, tendo em vista que "a estrutura de qualidades que alguém poderia alucinar é, de fato, uma parte própria do perfil sensível que exige mais [para ser instanciado] e do qual alguém está consciente no correspondente caso da visão" (JOHNSTON, 2004, p.136-137). Se quando vê algo, a pessoa está consciente do perfil sensível completo, quando alucina, está consciente somente de parte do perfil sensível da percepção correspondente. 
Então, para se constituir o perfil sensível alucinatório exige-se menos do que para se constituir o perfil sensível verídico.

Podemos entender, então, que o objeto da consciência alucinatória é entendido em termos do perfil sensível alucinado, que, por sua vez, é o elemento comum entre alucinações e percepções, sem ser o máximo fator comum para ambas essas experiências. É a esse perfil sensível compartilhado entre alucinações e percepções que Johnston (2004) recorre para explicar a indiscriminabilidade alucinatória. Alucinações são indiscrimináveis introspectivamente de percepções porque compartilham o perfil sensível alucinatório.

A exigência de que o perfil sensível verídico para ser instanciado requer particulares resguarda a demanda realista ingênua na qual o objeto físico é necessário para a natureza da percepção verídica. O perfil sensível perceptivo é instanciado por particulares, mas "quando o sistema visual falha, como nas alucinações, o perfil sensível apresenta complexos de qualidades e relações não instanciadas" (JOHNSTON, 2004, p. 135). Assim:

\begin{abstract}
A teoria do perfil sensível lança ao mar objetos como os sense data em favor de complexos em parte qualitativos, em parte relacionais, de modo que toda vez que são instanciados, são sempre instanciados em particulares físicos. Além disso, não existe a necessidade de uma categoria de qualia ou qualidades mentais além das categorias de qualidades ordinárias. A alucinação é um ato mental direcionado às qualidades sensíveis e relações, mas essas qualidades e relações são familiares, que, se instanciadas, poderiam somente ser instanciadas por particulares físicos (JOHNSTON, 2004, p. 146).
\end{abstract}

Objetos alucinados derivam das percepções verídicas, pois dependem de objetos físicos já vistos, de modo que as alucinações "imitam a extensão espacial e temporal e, por isso, imitam a particularidade" (JOHNSTON, 2004, p. 142). Assim, ainda que a experiência alucinatória leve a pessoa a julgar que está vendo algo físico, a alucinação não tem a fenomenologia perceptiva. Como o que aparece na alucinação de um tomate é uma parte do perfil sensível perceptivo, podemos aceitar a existência de um caráter fenomênico compartilhado por uma alucinação e uma percepção, determinado pelo perfil sensível comum a ambas experiências. Isso resguarda a tese segundo a qual a fenomenologia da percepção verídica é realizável somente na presença do objeto físico. 
Mediante o exposto, a resposta que Johnston (2004) oferece contra a tese do máximo fator comum posta pelo argumento causal é a seguinte. O perfil sensível alucinado, por ser uma parte do perfil sensível completo, ou verídico, não tem a condição necessária para a constituição e determinação da fenomenologia da percepção verídica. Se a realização do caráter fenomênico perceptivo requer objetos físicos e suas propriedades, o estado mental perceptivo só pode ocorrer na presença do objeto físico. Assim, a percepção verídica é uma experiência sui generis.

A teoria do perfil sensível também tem recursos para explicar transições experienciais sem ruptura introspectiva que poderiam ocorrer de uma alucinação para uma percepção e vice-versa. Conforme vimos no experimento do neurocirurgião, que ora faz a pessoa alucinar luzes no teto, ora retira o estímulo alucinatório, é necessário algo no nível mental para explicar a transição experiencial imperceptível à pessoa. É o perfil sensível alucinado, por ser o fator comum entre alucinações e percepções, o que explica a indiscriminabilidade quando se passa de uma experiência para outra.

Em resumo, a teoria do perfil sensível caracteriza as experiências alucinatórias como a consciência de perfis sensíveis não instanciados, que são partes dos perfis sensíveis das respectivas percepções verídicas. E caracteriza as experiências perceptivas como a consciência do perfil sensível instanciado em particulares físicos. Isso resguarda a visão relacional da percepção.

\section{Objeções}

Proponho dois problemas com a teoria do perfil sensível: 1) não explica como perfis sensíveis não instanciados apresentam qualidades à consciência da pessoa que alucina e; 2) o perfil sensível verídico é insuficiente para garantir que objetos físicos e suas propriedades tenham papel na determinação do caráter fenomênico das percepções verídicas. Isto, como veremos, é posto pelo problema da redundância explicativa. Tratemos inicialmente do primeiro problema.

Dada a teoria do perfil sensível, a experiência ocorrente na percepção verídica é uma questão de ter consciência de um perfil sensível instanciado, entendido como um complexo de qualidades sensíveis e relações instanciadas. Já a experiência alucinatória é uma questão de ter consciência de um perfil sensível não instanciado, 
pois as qualidades só poderiam ser instanciadas em particulares físicos. Nesse sentido, "a alucinação é um caso da consciência de uma maneira sensorial de apresentação sem a consciência de algo que instancia essa maneira sensorial de apresentação" (JOHNSTON, 2004, p. 150). Ou seja, embora o perfil sensível alucinatório seja caracterizado positivamente, o objeto da consciência alucinatório não teria o estatuto metafísico dos qualia ou dos sense data, pois qualia e sense data instanciam qualidades sensíveis.

Mas se o perfil sensível alucinatório não é instanciado, como se explica a vermelhidão (redness) que aparece à consciência da pessoa que alucina um tomate maduro?

Segundo Johnston:

\begin{abstract}
A ideia da consciência de perfis sensíveis não instanciados no cenário diante dos seus olhos pode vir a ser totalmente natural [...] no pitch dark $k^{13}$, alguém está visualmente consciente de certo matiz de preto (brain-greyness) e não de alguma coisa matizada de preto (brain-grey). Eu não diria que alguém não está consciente de nada no pitch dark, a questão que obviamente poderia surgir é se existe uma tintura ou tonalidade índigo com a qual alguém está consciente no pitch dark. O caso da consciência visual de uma qualidade no pitch dark deve se posicionar como uma dificuldade para aquelas visões que asseguram que em todos os casos que temos uma experiência visual, algum particular físico aparece para a pessoa, mesmo se ele estiver no ar ou diante dos olhos da pessoa. No pitch dark você não está vendo o ar ou o espaço diante dos seus olhos (JOHNSTON, 2004, p. 141).
\end{abstract}

Na experiência visual do pitch dark a pessoa está consciente de uma qualidade, mas nada estaria instanciando essa qualidade no cenário diante da pessoa. Analogamente, alucinações apresentariam qualidades não instanciadas à consciência da pessoa. Desse modo, a experiência visual do pitch dark corroboraria a ideia de perfis sensíveis não instanciados e, assim, a existência de qualidades não instanciadas na alucinação. Em complemento, Johnston afirma que perfis sensíveis não instanciados não enfrentam mais dificuldades ontológicas do que "itens com os quais muitos filósofos já estão razoavelmente confortáveis, a saber, aquelas maneiras de apresentação [sensorial] que não têm referente" (2004, p. 141).

Entretanto, recorrer à experiência visual do pitch dark para corroborar perfis sensíveis não instanciados não é explicar como itens mentais genuínos apresentam

13 Uma tradução para pitch dark é "escuro absoluto". O pitch dark é uma experiência que pode ser vivenciada dentro de cavernas quando apagamos as lanternas. 
qualidades à consciência da pessoa sem estarem instanciadas. Como eu posso experienciar a vermelhidão na alucinação de um tomate maduro sem que a qualidade esteja instanciada?

O intencionalismo ${ }^{14}$ oferece uma resposta plausível para a questão acima: a cor vermelha que aparece na alucinação do tomate maduro é uma questão do conteúdo representacional alucinatório. De fato, Johnston (2004, p. 155-161) propõe uma aproximação do relato que sua teoria oferece à natureza alucinatória com aquele que intencionalistas oferecem às alucinações quando recorrem ao conceito de "objeto intencional". Contudo, a teoria de Johnston (2004, p. 176, nota 2) diverge do intencionalismo ao defender que experiências alucinatórias não são proposicionais. Antes de envolver conteúdos proposicionais, a alucinação seria meramente um caso da consciência de complexos de qualidades sensíveis não instanciadas. E seria um equívoco entender os “objetos da consciência alucinatória” como análogos a "objetos intencionais", pois objetos intencionais não admitiriam a análise ação-objeto.

Então, a teoria do perfil sensível não explica como estamos conscientes de qualidades não instanciadas. E dizer que perfis sensíveis não instanciados não enfrentam mais dificuldades ontológicas enfrentadas por outras teorias da percepção não resolve o ponto. Ora, o que filósofas e filósofos da percepção estão buscando são soluções, não problemas.

O segundo, e mais grave problema com a teoria do perfil sensível, é o problema da redundância explicativa: objetos físicos seriam redundantes na determinação do caráter fenomênico das experiências perceptivas e, por conseguinte, não seriam necessários para o estado mental perceptivo. O perfil sensível verídico não garantiria a necessidade de objetos físicos para a realização do caráter fenomênico perceptivo, colocando em xeque a defesa do realismo ingênuo frente ao argumento causal. Para entendermos essa objeção, retomemos o argumento causal.

\footnotetext{
${ }^{14}$ Segundo o intencionalismo, as experiências são fundamentalmente representacionais, ou seja, têm um conteúdo intencional, o qual pode ser corrigido ou não. Como têm conteúdo intencional, elas envolvem atitudes proposicionais, tal como as crenças. Dado que o intencionalismo requer que o conteúdo de toda experiência, desde uma alucinação até uma percepção verídica, seja direcionado a um objeto, recorre-se à noção de objeto intencional para explicar para o que o conteúdo alucinatório é direcionado. Diferentemente de objetos físicos, sense data e qualia, objetos intencionais não instanciam qualidades.
} 
Segundo o argumento causal, se replicarmos as condições causais proximais de uma percepção verídica, obteremos uma alucinação com o mesmo caráter fenomênico da percepção verídica correspondente. $O$ argumento causal, como vimos, se baseia no princípio causal geral para sustentar que, se os estados neurais da alucinação do objeto $\mathrm{O}$ são os estados neurais da percepção do objeto $\mathrm{O}$, a pessoa que alucina tem a mesma experiência que teria caso estivesse vendo o objeto O. Das mesmas condições causais proximais infere-se que a pessoa que alucina tem a mesma experiência que teria na respectiva percepção verídica.

Como defende que objetos físicos e suas propriedades interferem na natureza das experiências perceptivas, isto é, objetos físicos são condições não causais necessárias para tais experiências, Johnston (2004) tem de negar o princípio causal geral para a relação causal perceptiva. No entanto, para não negar que nossas experiências perceptivas façam parte de uma ordem causal, Johnston (2004) tem de endossar um princípio causal restrito: para que o evento mental 1 seja do mesmo tipo que o evento mental 2, além das condições causais proximais que geram o evento 1 terem de ser as mesmas condições causais proximais que geram o evento 2 , o evento 1 e o evento 2 não podem diferir nas condições não causais necessárias para a ocorrência do evento mental 2.

Dado o princípio causal restrito, a alucinação difere da percepção por não ter a condição não causal necessária para a natureza da percepção verídica, qual seja, o objeto físico, ainda que a experiência alucinatória e a experiência perceptiva compartilhem condições causais proximais. Se alucinações causalmente condizentes e percepções verídicas não têm a mesma natureza, o argumento causal deixa de ser uma ameaça ao realismo ingênuo.

Entretanto, outra consequência pode ser derivada do princípio causal restrito. Se não existem condições não causais necessárias para a ocorrência da alucinação que estejam ausentes na percepção, e se uma alucinação e uma percepção podem ter as mesmas condições causais proximais, "qualquer que seja o tipo mais específico de evento que ocorre que é produzido quando temos uma alucinação causalmente condizente, o mesmo tipo de evento ocorre quando temos uma percepção verídica" (MARTIN, 2006, p. 369). Isso, argumentarei, gera uma instabilidade na teoria do perfil 
sensível quanto à determinação do caráter fenomênico perceptivo, expressada pelo problema da redundância explicativa.

Ao admitir que alucinações têm itens mentais genuínos (objetos da consciência alucinatórios ou perfis sensíveis alucinatórios) e endossar o princípio causal restrito, tem-se de admitir que o que determina a fenomenologia de uma alucinação causalmente condizente está presente na percepção verídica correspondente, pois não existem condições não causais presentes na alucinação que estejam ausentes na respectiva percepção.

Johnston (2004), então, tem o ônus de mostrar que o que determina a fenomenologia compartilhada por alucinações e percepções não é responsável pela fenomenologia perceptiva. Se todas as condições para a realização da fenomenologia alucinatória (portanto, para a realização do tipo de experiência que ocorre na alucinação) estão presentes na percepção verídica, a teoria do perfil sensível precisa garantir que o caráter fenomênico compartilhado por alucinações e percepções não entre em competição explicativa com o que o realista ingênuo supõe que uma percepção verídica tem de único: o caráter fenomênico realista ingênuo. Colocando o problema em outros termos, deve-se mostrar que a condição relevante para uma experiência ser uma percepção verídica (objeto físico) não separe as propriedades peculiares que supostamente existiriam na percepção verídica do papel explicativo que essas propriedades teriam para a natureza desse tipo de experiência.

Johnston (2004, p. 137) afirma que na percepção verídica a pessoa está consciente de "mais" do que a pessoa que alucina, na medida em que o perfil sensível completo é apresentado à pessoa somente na percepção verídica. O que impediria a competição explicativa entre a fenomenologia perceptiva e a fenomenologia alucinatória para o tipo de experiência que a pessoa tem na percepção verídica seria o fato de que o perfil sensível alucinado é uma parte do perfil sensível verídico. Desse modo, o tipo de experiência que se tem na alucinação não ocorreria na percepção verídica porque o perfil sensível alucinatório é incapaz de gerar uma experiência perceptiva verídica. Isso resguardaria a tese realista ingênua na qual a fenomenologia perceptiva depende de objetos físicos e suas propriedades para ser realizada.

Contudo, responder que o perfil sensível completo pode ser realizado somente na percepção verídica porque o perfil sensível alucinado é parte do perfil sensível Rev. Filos., Aurora, Curitiba, v. 33, n. 59, p. 652-676, mai./ago. 2021 
completo, ou seja, afirmar que a visão de um objeto físico faz com que a pessoa esteja consciente de "mais" do que estaria consciente na alucinação indiscriminável, não é suficiente para priorizar o relato realista ingênuo, portanto, de Johnston (2004), sobre a natureza da percepção verídica em detrimento do relato sobre a natureza da percepção verídica proposto pelo argumento causal, qual seja, que alucinações e percepções são experiências de um mesmo tipo metafísico, pois têm um máximo fator comum. Nós não temos como afirmar, com base na teoria do perfil sensível, que o que explica o que aparece introspectivamente à pessoa que vê um objeto físico diz respeito ao caráter fenomênico realista ingênuo e não ao caráter fenomênico compartilhado com uma alucinação causalmente condizente, pois podemos recorrer ao perfil sensível compartilhado para explicar a indiscriminabilidade alucinatória e a intuição de que a percepção verídica parece ser relacional ${ }^{15}$. De forma mais clara, se os objetos da consciência alucinatórios explicam aquilo que os objetos físicos deveriam explicar (segundo realistas ingênuos), por que os objetos da consciência alucinatórios deixam de ser suficientes para as explicações que se quer dar quando objetos físicos estão presentes?

A falta de uma resposta à questão acima coloca a teoria do perfil sensível numa posição instável em relação ao que determina o caráter fenomênico perceptivo, instabilidade alicerçada na redundância dos objetos físicos para o que eles deveriam explicar. Assim, ao não garantir que a fenomenologia perceptiva seja determinada por objetos físicos, a teoria do perfil sensível não mostra que o tipo de experiência que ocorre na percepção verídica é diferente do tipo de experiência que ocorre na alucinação. Essa instabilidade preditiva quanto à fenomenologia perceptiva não elimina a possibilidade de o perfil sensível compartilhado determinar inteiramente a fenomenologia da percepção verídica. Se esse for o caso, alucinações e percepções são experiências da mesma natureza.

Então, a teoria do perfil sensível não consegue mostrar que as propriedades peculiares que uma percepção verídica teria são relevantes para a natureza da percepção verídica, pois não explica por que o perfil sensível alucinatório deixa de ser suficiente para o tipo de experiência que ocorre na percepção verídica. Em outras

\footnotetext{
${ }^{15}$ Neste caso, a experiência perceptiva teria um aparente aspecto relacional. Assim, não seria relacional no sentido que os realistas ingênuos dizem que ela é.
} 
palavras, ao não eliminar a competição entre objetos dependentes da mente e objetos físicos na determinação fenomênica da percepção verídica, a teoria do perfil sensível falha na defesa do realismo ingênuo, pois objetos físicos passam a ser redundantes para a fenomenologia da percepção verídica. Consequentemente, alucinações causalmente condizentes continuam a ameaçar o realismo ingênuo.

Uma resposta ao problema da redundância explicativa seria afirmar que não existem itens mentais genuínos nas alucinações, pois deixa de existir a possibilidade de objetos da consciência alucinatórios e objetos físicos competirem pela determinação fenomênica da percepção verídica, isto é, não existiria a possibilidade de o caráter fenomênico perceptivo ser explicado por objetos da consciência alucinatórios. Contudo, negar que alucinações tenham uma natureza positiva é negar a teoria do perfil sensível, na medida em que perfis sensíveis alucinatórios envolvem itens mentais genuínos.

Como a teoria do perfil sensível não consegue mostrar que a experiência perceptiva verídica é relacional, não garante que o objeto físico tenha papel constitutivo e determinante no caráter fenomênico da percepção verídica. Portanto, é razoável afirmar que a teoria do perfil sensível não oferece ao realismo ingênuo uma resposta satisfatória contra o argumento causal.

\section{Conclusão}

$\mathrm{Na}$ defesa do realismo ingênuo contra o argumento causal e para escapar das deficiências explicativas dos disjuntivismos radicais, a teoria do perfil sensível tenta conciliar duas intuições em filosofia da percepção. A intuição realista ingênua de que a percepção verídica é fundamentalmente relacional e a intuição de que alucinações e percepções compartilham algo mental em comum e, portanto, itens mentais genuínos se apresentam à consciência da pessoa que alucina. Contudo, ao defender que a alucinação é uma questão de perfis sensíveis não instanciados, a teoria do perfil sensível não explica como a pessoa que alucina é consciente de qualidades não instanciadas. Mais contundente contra a teoria do perfil sensível é o problema da redundância explicativa. Quando as intuições acima descritas são tomadas em conjunto, a defesa do realismo ingênuo frente ao argumento causal torna-se inviável, 
pois gera-se uma instabilidade sobre o que determina o caráter fenomênico perceptivo. A caracterização positiva das alucinações faz com que objetos físicos sejam redundantes na determinação e constituição da experiência ocorrente na percepção verídica. Consequentemente, a natureza da experiência perceptiva verídica não dependeria de objetos físicos e suas propriedades. Então, é razoável afirmar que realismo ingênuo e objetos da consciência alucinatórios não são conciliáveis.

\section{Referências}

AUSTIN, J. L. Sense and Sensibilia. Oxford: Clarendon Press, 1962.

FFYTCHE, D. The Hallucinating Brain. In: F. Macpherson \& D. Platchias (ed.), Hallucination: Philosophy and Psychology, p.45-63. Cambridge: The MIT Press, p. 45-63, 2013.

FISH, W. Disjunctivism, Indistinguishability and the nature of Hallucination. In: HADDOCK, A.; MACPHERSON, F. (eds). Disjunctivism: perception, action, knowledge. Oxford: Oxford University Press, 2008. p. 144-167.

FISH, W. Perception, Hallucination and Illusion. Oxford: University Press, 2009.

HINTON, J. M. Visual Experiences. Mind, v. 76, p. 212-227, 1967.

JOHNSTON, M. The obscure object of hallucination. Philosophical Studies, v. 120, p. 113-183, 2004.

KIM, J. Supervenience and Mind. Cambridge: Cambridge University Press, 1993.

MARTIN, M. G. F. The limits of self-awareness. Philosophical Studies, v. 120, p. 37-89, 2004.

MARTIN, M. G. F. On Being Alienated. In: GENDLER, T. S.; HAWTHORNE, J. (eds). Perceptual Experience. Oxford: Oxford University Press, 2006.

O’SHEA, M. Cérebro. Trad. Iuri Abreu. Porto Alegre: L\&PM, 2010 [2005].

RECEBIDO: $21 / 02 / 2020$

RECEIVED: 02/21/2020

APROVADO: $10 / 07 / 2021$

APPROVED: 07/10/2021 